\title{
BMJ Global Health What questions we should be asking about COVID-19 in humanitarian settings: perspectives from the Social Sciences Analysis Cell in the Democratic Republic of the Congo
}

Simone E Carter (D) , ${ }^{1}$ Nina Gobat, ${ }^{2}$ Jérôme Pfaffmann Zambruni, ${ }^{3}$ Juliet Bedford, ${ }^{4}$ Esther van Kleef, ${ }^{5}$ Thibaut Jombart, ${ }^{6,7}$ Mathias Mossoko, ${ }^{8}$ Dorothée Bulemfu Nkakirande, ${ }^{8}$ Carlos Navarro Colorado, ${ }^{3}$ Steve Ahuka-Mundeke ${ }^{9}$

To cite: Carter SE, Gobat N, Pfaffmann Zambruni J, et al. What questions we should be asking about COVID-19 in humanitarian settings: perspectives from the Social Sciences Analysis Cell in the Democratic Republic of the Congo. BMJ Global Health 2020;5:e003607. doi:10.1136/ bmjgh-2020-003607

Handling editor Seye Abimbola

Received 1 August 2020 Revised 31 August 2020 Accepted 1 September 2020

Check for updates

\section{(c) Author(s) (or their} employer(s)) 2020. Re-use permitted under CC BY-NC. No commercial re-use. See rights and permissions. Published by BMJ.

For numbered affiliations see end of article.

Correspondence to Simone E Carter; SCARTER@UNICEF.ORG

\section{INTRODUCTION}

COVID-19 is but one of many public health crises facing the people of the Democratic Republic of the Congo (DRC). On 25 June 2020, the DRC government announced the end of the country's largest Ebola outbreak on record and the second largest Ebola outbreak worldwide, a mere few weeks after a new outbreak (11th) started on 1 June 2020, in Mbandaka, Equateur Province. ${ }^{1}$ In 2019 , measles claimed the lives of over 6000 people including 4500 children under the age of 5, malaria killed 17000 individuals, and cholera outbreaks affected 20 of 26 provinces, resulting in 31000 cases. $^{2}$

These epidemics arise among communities living in overwhelming poverty, affected by conflict and regular population displacement. ${ }^{3}$ The DRC is not a unique situation. Across many parts of the world, governments, humanitarian responders and communities confront multiple challenges where the response to public health emergencies must compete for human, financial and health service resources. Humanitarian responses to these crises are hampered by weak public health structures, poorly resourced health systems, and in some regions protracted insecurity and conflict. Tackling epidemics under these complex social, political and economic realities requires integrated and multidisciplinary sources of data and evidence to inform response strategies. ${ }^{4}$

The use of social and behavioural sciences evidence in outbreak response has increased over the recent years, gaining particular traction since the 2014-2016 Ebola epidemic

\section{Summary box}

Social sciences research for epidemic response has evolved to provide critical evidence needed for outbreak prevention and control and is most impactful when included as part of a multidisciplinary, integrated package.

- Outbreak analytics is a data science which encompasses multiple methods in epidemiological analysis and modelling to inform outbreak response.

We propose to complement this with data and analytical approaches from multiple disciplines to provide a holistic understanding which not only maps and models epidemiological data but seeks to provide context and an understanding for potential cause and effect, thus creating an integrated multidisciplinary outbreak analytics (IMOA) model. Drawing on this experience, we have identified four questions to shape IMOA: (1) What are the impacts on healthcare-seeking behaviour, changing trends in service perception, and the availability, access and use of health services? (2) What are the perceptions and behaviours of healthcare workers and what impact does this have on outbreak dynamics? (3) What are individual and community understanding, perceptions and practices relevant to adapting public health and social measures? (4) What mechanisms are used to include gender and what impacts do these have on outbreak dynamics?

in West Africa. ${ }^{5}$ Social science analyses for epidemic response have evolved to provide critical evidence needed for outbreak prevention and control and are most impactful when included as part of a multidisciplinary, integrated package. Outbreak analytics is a data science which encompasses multiple methods in epidemiological analysis and modelling to inform outbreak response. ${ }^{6}$ We propose 
to complement this with data and analytical approaches from multiple disciplines to provide a holistic understanding which not only maps and models epidemiological data to, for example, assess trends, burden and risk factors, but seeks to provide context and an understanding for potential cause and effect, thus creating an integrated multidisciplinary outbreak analytics (IMOA) model.

An important case for this was demonstrated during the Ebola outbreak in Eastern DRC. ${ }^{7}$ The Social Sciences Analytics Cell (CASS) was established under the Ministry of Health (MoH) and led by UNICEF, in collaboration with national and international, academic and humanitarian partners. The CASS is the first field-based, multiactor, operational research mechanism providing rapid social and behavioural sciences evidence used to systematically inform real-time epidemiological analyses, government and response decision-making in an outbreak. Working hand in hand with (field) epidemiologists, statisticians and modellers, the CASS provided invaluable insights into observations from epidemiological data and analyses, helping not only to direct and refine epidemiological models, but also shedding lights on unexpected analytical results through accelerated indepth investigations in the field. By bringing social, behavioural and health services analyses to the research group, the CASS provides an essential complement to outbreak analytics, ${ }^{8}$ creating a mechanism for producing IMOA for programmatic and strategic decision-making. During the Eastern DRC Ebola outbreak, the CASS conducted 57 studies, many in response to direct requests from the DRC MoH, and codeveloped 112 evidence-based recommendations with $\mathrm{MoH}$ and response actors to guide response strategies. A monitoring system to track recommendations allowed researchers and decision-makers to demonstrate accountability and evidence-based decision-making. ${ }^{7}$ Examples of integrated studies are summarised in table 1.

Drawing on this experience, the CASS has identified four priority questions to shape IMOA agendas in humanitarian settings. These priorities have been identified to improve effectiveness and accountability of humanitarian programmes implemented during COVID-19, aligning with the social science research agenda set out by the WHO COVID-19 Research Roadmap. ${ }^{9}$

\section{WHAT ARE THE IMPACTS ON HEALTHCARE-SEEKING BEHAVIOUR, CHANGING TRENDS IN SERVICE PERCEPTION, AND THE AVAILABILITY, ACCESS AND USE OF HEALTH SERVICES?}

Monitoring if and how health services are being used and how healthcare provision and resources may change or be redirected towards the COVID-19 response provides signals to identify unattended population health needs. These arise through perceived and real difficulties experienced by affected populations related to the availability and access to services, which may result in secondary impacts on health outcomes beyond COVID-19. In efforts to combat Ebola in Eastern DRC, attention and resources were diverted away from health facilities providing essential non-Ebola care such as vaccination, leaving already vulnerable groups more susceptible to preventable diseases such as measles, malaria or cholera. This effect was illustrated by 6000 deaths from measles reported at the same time in $2019 .^{2}$

The West African Ebola outbreak (2014-2016) saw significant declines in the use of health services, including maternal, child and reproductive health, as well as sexual and gender-based violence (SGBV) services. ${ }^{10}{ }^{11}$ To mitigate these impacts, during the DRC outbreaks (both in Equateur and Eastern DRC) authorities implemented different levels of free healthcare policies which were adapted over time. Although there was reported distrust in the quality of free care, rapid studies on healthcareseeking behaviour (including documenting patient registries) quickly highlighted increases in the use of free healthcare services. ${ }^{12} 13$ Data were matched with trend analyses from District Health Information Software 2 (DHIS2) and triangulated with community reports of overcrowding in healthcare centres. ${ }^{14}$ These data were integrated, and analysis of multiple data sources including epidemiological, health services and behavioural studies provided the response leadership with a greater understanding of the potential impacts of overcrowding on delayed care for patients, patient-physician trust and willingness to seek care. They further shed light on possible negative impacts on the quality of care and contributed to greater understanding and possible explanations for high levels of nosocomial infections, including among children under $5 .^{15-19}$

Early reports suggest that COVID-19 threats to healthcare access will disproportionately impact vulnerable groups (such as survivors of SGBV, people living with HIV, women with sexual and reproductive health needs, and children requiring vaccination).$^{20-23}$ Community perceptions relating to how health services are provided and their ability to access them may affect healthcareseeking behaviour, regardless of whether service provision has in fact changed or not. As COVID-19 spreads, ill-equipped health facilities risk becoming sources of infection and transmission. ${ }^{24}$ Individual and community priorities also shift, with increased domestic responsibilities, particularly for women, relating to childcare and care for sick relatives. ${ }^{22}$ Further barriers to access can arise if healthcare facilities start charging for services in order to make up for lost income..$^{25}$ A reduction in healthcareseeking may result in a decrease in case notification for multiple diseases, reducing a country's ability to detect and respond to new outbreaks in a timely fashion.

Where epidemiological analyses explore absolute differences in healthcare-seeking across locations, groups or time, real-time social sciences analyses provide explanation for changing perceptions and healthcare-seeking behaviours. Triangulation of data which monitor the changes in epidemiological and behavioural evidence over time, location, as well as different events, and the implementation of various public health and social 


\begin{tabular}{|c|c|c|c|}
\hline Study & Thematic analysis & Date & Process for analysis \\
\hline 1 & $\begin{array}{l}\text { Understanding delays in } \\
\text { treatment-seeking. }\end{array}$ & July 2019 & $\begin{array}{l}\text { Epidemiological data found continued long delays in treatment- } \\
\text { seeking (5-12 days) which increased the risk of mortality. CASS meta- } \\
\text { analysis reviewed existing qualitative and quantitative data to explain } \\
\text { potential causes in delays and recommendations for how to reinforce } \\
\text { treatment-seeking. }\end{array}$ \\
\hline 2 & $\begin{array}{l}\text { Possible explanations } \\
\text { for variations in } \\
\text { community deaths. }{ }^{42}\end{array}$ & July 2019 & $\begin{array}{l}\text { Epidemiological data indicated increased community deaths in } \\
\text { specific locations. CASS analysis explored perceptions around } \\
\text { transmission and risks related to community deaths in the same } \\
\text { locations to understand their potential cause and the impact they may } \\
\text { have based on behaviour around deaths. }\end{array}$ \\
\hline
\end{tabular}

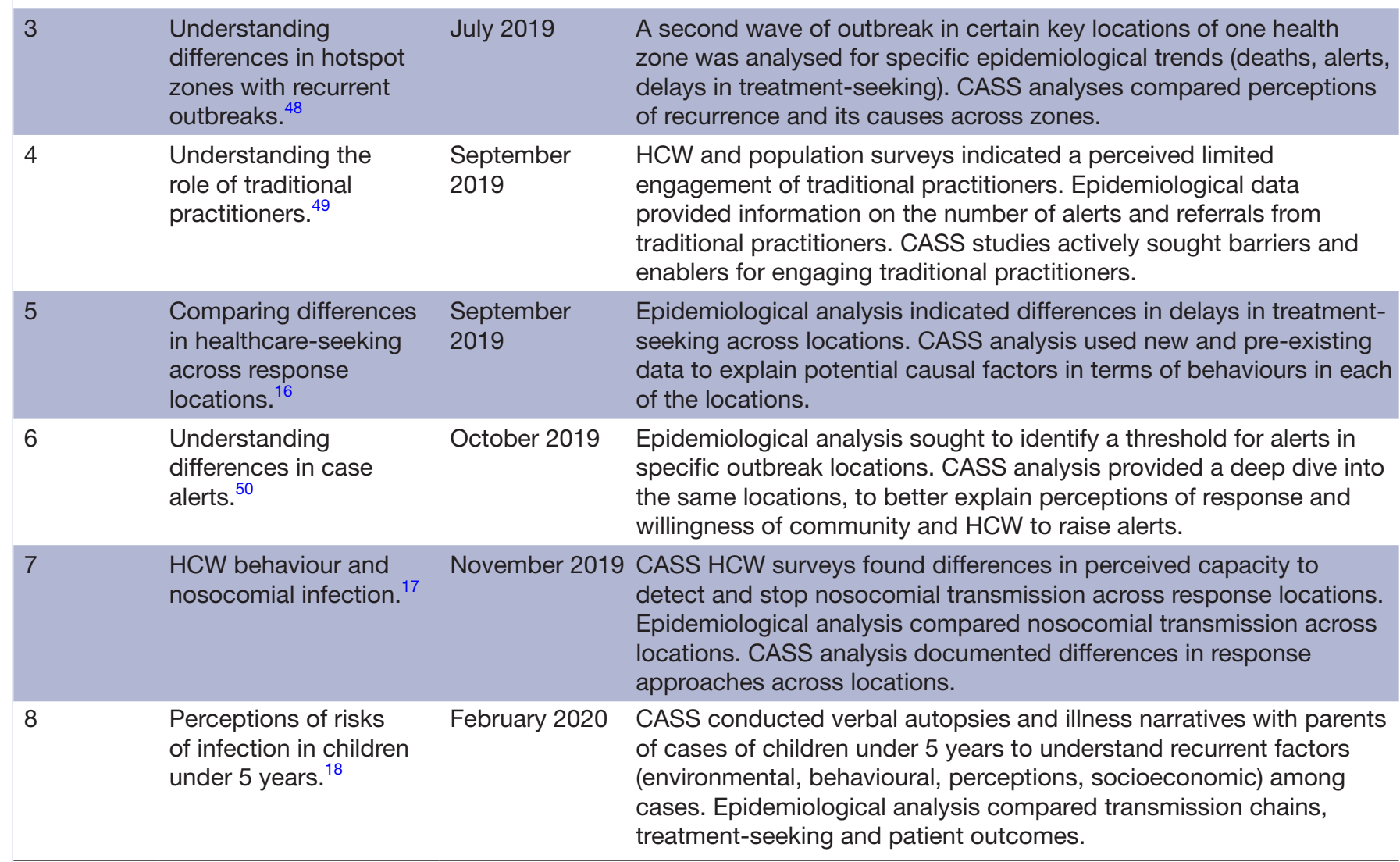

CASS, Social Sciences Analytics Cell; HCW, healthcare worker.

measures (PHSM), provides a comprehensive assessment of the anticipated impact of a response on healthcareseeking. This will enrich understanding of healthcareseeking behaviours before and during an outbreak and help to anticipate changes that may result from established PHSM. This will allow service provision to be sufficiently adapted to ensure continued access and improved health outcomes.

\section{WHAT ARE THE PERCEPTIONS AND BEHAVIOURS OF HEALTHCARE WORKERS AND WHAT IMPACT DOES THIS HAVE ON OUTBREAK DYNAMICS?}

Healthcare workers (HCWs) in humanitarian settings work in contexts of multiple public health crises in addition to COVID-19. The onset of COVID-19, much like any new outbreak, directly impacts their work in multiple ways, for example, through limitations in resources (reduced or limited), stigma, increased fear and uncertainty, circulation of (mis)information, and frequent changes to infection prevention and control (IPC) procedures, healthcare policies, and service provision. ${ }^{26} 27$ These factors can impact patients, HCWs and their families not only in terms of risk of exposure to COVID-19, but secondary health, socioeconomic and social risks.

During the Eastern DRC Ebola outbreak, despite consistent trainings to support HCWs, nosocomial infections continued to be present, and tensions and distrust between communities and HCWs continued to rise. ${ }^{28} 29$ Not only are HCWs in humanitarian contexts faced with the responsibility to protect their patients and themselves, they are often expected to take on additional, new responsibilities, such as raising alerts or applying new 
protocols for IPC. This can create distrust between themselves and their patients, as was seen in Eastern DRC, where communities falsely accused HCWs of working for the response and earning money for sending all sick to the Ebola Treatment Centre (ETC) ${ }^{29}{ }^{30}$ In humanitarian settings, if this reduces healthcare use, it may also have socioeconomic impacts on the HCW. In Eastern DRC, HCWs in private facilities reported that a reduction in the number of patients left them unable to feed their own families. Attempting to regain clients, they rejected the IPC protocols. In public, free care facilities, HCWs and communities reported overcrowding and HCWs' incapacity to apply IPC protocols due to increased number of patients and limited number of beds. ${ }^{30}{ }^{31}$ HCWs consequently feared putting both themselves and their patients at risk of infection. ${ }^{31}$

The CASS HCW surveys conducted in North Kivu found that, although HCWs reported understanding the required IPC measures, many continued to feel unable to talk to patients about Ebola, nor to prevent transmission within their facilities. The areas where HCWs were least likely to have self-reported capacity to stop transmission were also the areas with the highest number of nosocomial infections. ${ }^{17}$

Integrated, multidisciplinary analyses seek to include HCW experiences, not only their knowledge but also their perceptions of capacity and perceived secondary impacts on health services as well as community-HCW dynamics. This can provide a more comprehensive understanding of the potential underlying causes of health services use, secondary health outcomes and trends in outbreak analytics. Integrated analyses can explain differences in rates of nosocomial infection across locations and over time, and also inform the kind of HCW support required to mitigate risks. These data would also complement health services use data, providing insights from HCWs to explain any changes in services use patterns over time.

\section{WHAT ARE INDIVIDUAL AND COMMUNITY UNDERSTANDING, PERCEPTIONS AND PRACTICES RELEVANT TO ADAPTING PHSMS?}

Across outbreaks, as in COVID-19, different models have been used to predict intervention effectiveness. Their application and feasibility in humanitarian contexts, however, require an integrated understanding of the communities and contexts in which they are applied. ${ }^{32} 33$

PHSMs may include school and business closures, mask wearing, as well as IPC measures such as decontamination, burial practices and isolation of sick patients. ${ }^{34}$ These measures are important in order to slow transmission of COVID-19 and reduce the burden on healthcare systems. Their estimated effectiveness, based on epidemiological modelling, has shaped national policies globally. ${ }^{35}$ However, for PHSMs to be effective in practice, communities need to trust they work, and be willing and able to practise or engage with them. ${ }^{3637}$ Acceptance and compliance rely on feasibility of adherence and a belief that the impact will be positive. ${ }^{38}$

Epidemiological modelling in the West African Ebola outbreak was used to estimate effectiveness of various interventions, including IPC..$^{39} 40$ CASS studies during the Eastern DRC Ebola outbreak found that many IPC measures such as decontamination were known strategies and perceived to be effective in stopping disease transmission; however, during the Ebola response they were conducted by responders who were not known to the communities, rather than those who would normally be responsible for IPC. This created distrust and perceptions that the decontamination was being used to spread Ebola. $^{29}$ Furthermore, decontamination teams also burned household items (clothes, mattresses), which had socioeconomic impacts and resulted in families feeling unable to participate in the intervention. ${ }^{41}$

Social sciences studies which identify what IPC measures are already known, what factors influence their acceptance and what are the requirements for communities to actively engage in such measures can inform how to improve the effectiveness of community-based IPC strategies. Integrated social sciences data with IPC scorecard evaluations can provide insights regarding differences in structure and HCW uptake of measures, which could be associated with health outcomes from epidemiological data, for example, nosocomial infection rates. Epidemiological modelling could be used to estimate the level of nosocomial transmission subject to uptake of IPC, structural factors such as water availability or integrate with social sciences data on self-reported capacity by HCWs. Integrated analysis requires good documentation allowing association between data sources, for example, the patient's place of origin (facility name or number).

During the Ebola outbreak in both Equateur (2018) and Eastern DRC, IPC measures directed individuals and families to wait for test results before caring for sick or dead family members; however, this proved very difficult for the families. Although individuals may recognise the risk that touching a sick or dead person may create, due to social norms, pressure, beliefs and practices they may feel unable or unwilling to engage in the required IPC measures. ${ }^{42}$

Research that seeks to understand how social norms and practices related to IPC are perceived by the community could inform decision-making on how (and by whom) they could be influenced. This information can be translated into adapted IPC strategies, for example, providing materials directly to communities and households so families can safely care for the sick or the dead. Integrated, epidemiological analyses can provide key information on where there may be greater delays in community engagement with safe and dignified burials or fewer alerts for community deaths, as well as provide critical information on transmission chains related to community deaths which may result in increased community transmission. Social sciences research can then further explain possible determinants related to these 
differences to support community and context-specific response strategies.

\section{WHAT MECHANISMS ARE USED TO INCLUDE GENDER AND WHAT IMPACT DO THESE HAVE ON OUTBREAK DYNAMICS?}

Understanding the roles women play in outbreak dynamics and response interventions is critical to stopping transmission. (Gender)-inclusiveness in COVID-19 is essential to understand who and how individuals and communities have or could be affected. (Gender)inclusive strategies and interventions are required for community engagement in life-saving activities such as contact tracing, surveillance, healthcare-seeking and infection prevention control measures.

During the Eastern DRC Ebola outbreak, the first surveillance reporting forms lacked key gender-specific information (including sociodemographic information, and whether a woman was pregnant or breast feeding). ${ }^{43}$ Vaccination data were not made available disaggregated by age or sex. In these same first months of the outbreak, CASS studies found that pregnant and breastfeeding women who were not eligible for the vaccine reported being excluded from surveillance and household visits. This increased their perceived risk of death, their fear in treatment-seeking and refusal to go to an ETC. ${ }^{44}$ The lack of gender disaggregated vaccination data limited a more integrated analysis and prevented a more comprehensive understanding of potential factors for exposure and risk among pregnant and breastfeeding women, and how these may influence or be influenced by outbreak dynamics. ${ }^{445}$

During outbreaks in humanitarian settings, women may be more at risk, both as domestic caregivers (for sick, elderly and children) and as front-line formal and informal healthcare. ${ }^{46}$ In the Eastern DRC Ebola outbreak, female participants in CASS studies reported feeling at a greater risk of exposure to Ebola due to limited information on how women could protect themselves, their roles as caregivers for the sick, and the vaccine ineligibility for pregnant and breastfeeding women (until July 2019). CASS studies found that women systematically reported being less involved in the response interventions, which they provided as explanation for their reticence to engage in healthcare-seeking or IPC measures.

Key data required to understand the outbreak dimensions should be developed with women and specific to context. In addition to disaggregation by age and sex, surveillance and vaccination forms, among other data points, must capture information on occupation (considering context-specific HCW roles such as a traditional healer and pharmacist), socioeconomic status and whether a woman is pregnant or breast feeding (two separate indicators). Information on work, for example if the individual works in transport or domestic work, can inform about potential spread to other households or locations. Understanding not only the age and sex of those affected, but potential socioeconomic factors can help inform rapid surveys to better understand the related drivers for transmission among specific groups. Without these critical social epidemiological data from onset, important explanations in outbreak trends could be missed.

Research should not wait to understand the gendered impacts of COVID-19 until after the outbreak, but rather ensure that studies focus on real-time analyses to inform decision-making. When social scientists (including social epidemiologists) work with surveillance and epidemiology teams from onset, and when both these groups ensure women's contribution to the design and development of data and research tools, and in analyses, they are more likely to identify appropriate information which is critical for an improved understanding of the outbreak and its dynamics.

\section{CONCLUSION}

The COVID-19 response is heavily driven by basic epidemiological analysis and modelling, particularly in middleincome and high-income countries. In humanitarian settings, this approach is unlikely to be sufficient when one considers the many socioeconomic factors, security and public health priorities, including concurrent outbreaks of other diseases. These factors further influence the availability of routinely collected data and set-up of surveillance systems, which in turn challenge the reliability of modelling work and predictions. Based on the body of field studies applying IMOA during the recent Ebola outbreak in Eastern DRC, we highlight key social sciences research questions which can complement outbreak analytics and in turn contribute to a greater understanding of outbreak dynamics and inform strategy and response in humanitarian settings.

In humanitarian settings under COVID-19, researchers working in statistical modelling, epidemiological and health services analyses, and social sciences must work together. They must also bring in additional sources of data, such as mapping of movements, prices and events, to develop a comprehensive and integrated understanding of the outbreak and its collateral effects. To inform public health strategies and interventions, operational field IMOA researchers must invest in strong collaborative processes with incountry decision-makers who lead response efforts. Studies should be developed jointly between ministries of health, response actors (national and international non-governmental organisations, United Nations) and researchers.

IMOA researchers should work closely with these actors to set up plans for the use of study results and systematically review research results to adapt programmes and research agendas, including adapting the types of data collected and methodologies used. Further, mechanisms to track and improve the use of IMOA should be set up. Similar approaches will be paramount in maximising the effectiveness and accountability of the response to 
COVID-19 in the complex landscape of humanitarian settings, in DRC and beyond.

\section{Author affiliations}

Public Health Emergencies, UNICEF, Geneva, Switzerland

${ }^{2}$ Nuffield Department of Primary Care Health Sciences, University of Oxford, Oxford, UK

${ }^{3}$ Public Health Emergencies, UNICEF, New York, New York, USA

${ }^{4}$ Anthrologica, Banbury, UK

${ }^{5}$ Department of Public Health, Prince Leopold Institute of Tropical Medicine, Antwerpen, Belgium

${ }^{6}$ Department of Infectious Disease Epidemiology, London School of Hygiene \& Tropical Medicine, London, UK

${ }^{7}$ UK Public Health Rapid Support Team, Public Health England, London, UK

${ }^{8}$ Direction Générale de Lutte contre la Maladie/ Direction Surveillance

Epidemiologique, Ministere de la Sante Publique, Kinshasa, Congo (the Democratic Republic of the)

${ }^{9}$ Departement de Virologie, Institut National de Recherche Biomédicale, Kinshasa, Congo (the Democratic Republic of the)

Twitter Simone E Carter @simone_tweets

Acknowledgements This paper and the studies from which it draws examples are the result of the dedication and work of local and national social sciences and epidemiological teams. The authors would like to express their sincere gratitude to those who remain dedicated to the work in the DRC and continue to identify new and adaptive ways to use evidence for action in outbreaks. The set-up of both teams would not have been possible without the support from the DRC Ministry of Health, the WHO, UNICEF, the CDC, MSF-Epicentre, IFRC and UNICEF, as well as key implementing partners.

Contributors SEC: led the Social Sciences Analytics Cell, developed and drafted the manuscript. NG, JPZ, JB: manuscript revision and contribution. EVK: contributed to the in-country application of integration of CASS and epidemiological analysis, and manuscript revision and contribution. TJ: led the development of the outbreak analytics paper from which the IMOA approach in this paper was developed, contributed to the in-country application of integration of CASS and epidemiological analysis, and manuscript revision and contribution. MM: supervised the integrated CASS and epidemiological cells, and manuscript revision. DBN: worked with the integrated CASS and epidemiological cells, and manuscript revision. CNC: supported the conceptualisation of the paper, and manuscript revision and contribution. SA-M: oversaw the coordination and integration of the CASS and the epidemiological analysis cell to inform response interventions, and manuscript revision and contribution.

Funding The authors have not declared a specific grant for this research from any funding agency in the public, commercial or not-for-profit sectors.

Competing interests None declared.

Patient consent for publication Not required.

Provenance and peer review Not commissioned; internally peer reviewed.

Data availability statement All data relevant to the study are included in the article or uploaded as supplementary information.

Open access This is an open access article distributed in accordance with the Creative Commons Attribution Non Commercial (CC BY-NC 4.0) license, which permits others to distribute, remix, adapt, build upon this work non-commercially, and license their derivative works on different terms, provided the original work is properly cited, appropriate credit is given, any changes made indicated, and the use is non-commercial. See: http://creativecommons.org/licenses/by-nc/4.0/.

ORCID iD

Simone E Carter http://orcid.org/0000-0003-3818-3538

\section{REFERENCES}

1 World Health Organisation. Ebola in the democratic republic of the Congo: health emergency update, 2020. Available: https://www. who.int/emergencies/diseases/ebola/ebola-health-update-équateurprovince-democratic-republic-of-the-congo-2020 [Accessed 11 Jul 2020].

2 Ingram S. On life support, 2020. Available: https://www.unicef.org/ sites/default/files/2020-03/On-life-support-DRC-2020.pdf
3 ECHO. Democratic Republic of the Congo - escalating conflict and displacement (DG ECHO, UN, INGOs, media) (ECHO Daily flash 20 December 2019) - democratic republic of the Congo ReliefWeb, 2019. Available: https://reliefweb.int/report/democraticrepublic-congo/democratic-republic-congo-escalating-conflict-anddisplacement-dg [Accessed 11 Jul 2020].

4 Bedford J, Farrar J, Ihekweazu C, et al. A new twenty-first century science for effective epidemic response. Nature 2019;575:130-6.

5 Bardosh K, de Vries D, Stellmach D. Towards people-centred epidemic preparedness \& response, 2019.

6 Polonsky JA, Baidjoe A, Kamvar ZN, et al. Outbreak analytics: a developing data science for informing the response to emerging pathogens. Philos Trans R Soc Lond B Biol Sci 2019;374:20180276.

7 CASS. Cellule d'analyse en sciences sociales (CASS) for ebola google drive, 2019. Available: https://drive.google.com/drive/folders/ 1H3JkO3YhEU5TT99-Lk_sAwXRuE9UUkMY [Accessed 27 Jul 2020].

8 Anderson JN, Nevin RL. Prohibiting direct medical care by US military personnel in foreign disaster relief: arguments from the Ebola disaster. Med Confl Surviv 2016;32:1-7.

9 World Health Organisation. A coordinated global research roadmap: 2019 novel coronavirus, 2020.

10 Delamou A, Ayadi AME, Sidibe S, et al. Effect of Ebola virus disease on maternal and child health services in guinea: a retrospective observational cohort study. Lancet Glob Health 2017;5:e448-57.

11 Harman S. Ebola, gender and conspicuously invisible women in global health governance. Third World Q 2016;37:524-41.

12 CASS. Analyses de l'étude sur les connaissances perception \& comportements de santé de la communauté Butembo-KatwaKalunguta, 2019.

13 Hung YW, Law MR, Cheng L, et al. Impact of a free health care policy in the Democratic Republic of the Congo during an Ebola outbreak: an interrupted time-series analysis. SSRN Journal 2019.

14 DHIS. Collect, manage, visualize and explore your data DHIS2. Available: https://www.dhis2.org/ [Accessed 27 Jul 2020].

15 CASS; Epi Cell. Deep dive Itinéraires Thérapeutiques Juillet, 2019.

16 CASS; Epi Cell. Deep Dive- Itinéraires Thérapeutiques Béni Septembre, 2019.

17 CASS; Epi Cell. Deep Dive- Chaine de transmissions infections nosocomials et personnel de santé, 2019.

18 CASS; Epi Cell. Analyses approfondies : perceptions des risques et infections chez les enfants de moins de 5 ans, 2020.

19 UNICEF. Free healthcare: the other side of the coin - democratic republic of the Congo ReliefWeb, 2018. Available: https://reliefweb. int/report/democratic-republic-congo/free-healthcare-other-sidecoin [Accessed 11 Jul 2020].

20 Roberton T, Carter ED, Chou VB, et al. Early estimates of the indirect effects of the COVID-19 pandemic on maternal and child mortality in low-income and middle-income countries: a modelling study. Lancet Glob Health 2020;8:e901-8.

21 UNDESA. Everyone included: social impact of COVID-19 DISD, 2020. Available: https://www.un.org/development/desa/dspd/ everyone-included-covid-19.html [Accessed 27 Jul 2020].

22 CARE. Rapid Gender Analysis for COVID 19 East, Central and Southern Africa - Angola ReliefWeb, 2020. Available: https:// reliefweb.int/report/angola/care-rapid-gender-analysis-covid-19east-central-and-southern-africa [Accessed 27 Jul 2020].

23 Human Rights Watch. Human rights dimensions of COVID-19 response, 2020. Available: https://www.hrw.org/news/2020/03/ 19/human-rights-dimensions-covid-19-response\#_Toc35446586 [Accessed 11 Jul 2020].

24 McMahon DE, Peters GA, Ivers LC, et al. Global resource shortages during COVID-19: bad news for low-income countries. PLoS Negl Trop Dis 2020;14:e0008412.

25 CASS. Présentations des résultats études CASS (toutes prés.) - Google Drive, 2019. Available: https://drive.google.com/drive/ folders/1hbEbEtAvCFIs4f7Ot1Ai5OGOotrWBhjO [Accessed $27 \mathrm{Jul}$ 2020].

26 McMahon SA, Ho LS, Brown $\mathrm{H}$, et al. Healthcare providers on the frontlines: a qualitative investigation of the social and emotional impact of delivering health services during Sierra Leone's Ebola epidemic. Health Policy Plan 2016;31:1232-9.

27 Smith C. Th structural vulnerability of healthcare workers during Covid-19: observations on the social contact of risk and equitable distribution of resources, 2020.

28 Ministère de la Santé (Commission PCl). Aperçu général sur les infections nosocomiales, 2019.

29 CASS. Analyses de l'étude sur les connaissances, perceptions, comportements de sante de la communautaire, 2020.

30 CASS. Reconstruire la confiance des communauté affectées par la MVE dans le personnel de santé, 2019. 
31 CASS. Perceptions des services de santé et leurs utilisations en fonction de l'évolution de l'épidémie et des interventions de la riposte Beni, 2018.

32 LSHTM. Strategies combining self-isolation, moderate physica distancing and shielding likely most effective COVID-19 response for African countries LSHTM, 2020. Available: https://www.Ishtm. ac.uk/newsevents/news/2020/strategies-combining-self-isolationmoderate-physical-distancing-and-shielding [Accessed 27 Jul 2020]

33 van Zandvoort $\mathrm{K}$, Jarvis $\mathrm{Cl}$, Pearson CA B, et al. Response strategies for COVID-19 epidemics in African settings: a mathematical modelling study, 2020. Available: https://cmmid. github.io/topics/covid19/reports/LSHTM-CMMID-20200419Covid19-Africa-strategies.pdf

34 WHO. Taxonomy and glossary of public health and social measures that may be implemented to limit the spread of Covid-19, 2020.

35 Enserink M. Mathematics of life and death: how disease models shape national shutdowns and other pandemic policies. Science 2020.

36 Murray J, Craigs CL, Hill KM, et al. A systematic review of patient reported factors associated with uptake and completion of cardiovascular lifestyle behaviour change. BMC Cardiovasc Disord 2012;12:120.

37 Dreibelbis $\mathrm{R}$, Winch $\mathrm{P}$, Leontsini $\mathrm{E}$, et al. The integrated behavioural model for water, sanitation, and hygiene: a systematic review of behavioural models and a framework for designing and evaluating. BMC Public Health 2013;13.

38 Becker $\mathrm{MH}$, Maiman LA. Sociobehavioral determinants of compliance with health and medical care recommendations. Med Care 1975;13:10-24.
39 Kucharski AJ, Camacho A, Flasche S, et al. Measuring the impact of Ebola control measures in Sierra Leone. Proc Natl Acad Sci U S A 2015;112:14366-71.

40 Chowell G, Nishiura $\mathrm{H}$. Transmission dynamics and control of Ebola virus disease (EVD): a review. BMC Med 2014;12:196

41 CASS. Analyses de l'étude sur les connaissances, perceptions, comportements de santé de la communauté Mabalako \& Mandima, 2019.

42 CASS; Epi Cell. Deep Dive- Décès Communautaire, 2019.

43 CASS. Social science support for COVID-19: lessons learned brief 1 what social sciences researchers working in humanitarian contexts (sub-Saharan Africa) should be asking in COVID-19 and why, 2020.

44 CASS. Perceptions des risques chez les femmes enceintes et allaitantes, 2018.

45 CASS. Social science analysis cell (CASS), 2020.

46 Smith J. Gender matters in responding to major disease outbreaks like Ebola, 2019. Available: https://theconversation.com/gendermatters-in-responding-to-major-disease-outbreaks-like-ebola120524 [Accessed 12 Jul 2020].

47 Villareal A. Coronavirus pandemic exacerbates inequalities for women, UN warns world news the guardian, 2020. Available: https://www.theguardian.com/world/2020/apr/11/un-coronaviruspandemic-gender-inequalities-women [Accessed 12 Jul 2020].

48 CASS; Epi Cell. Deep dive hotspot Beni Juillet, 2019.

49 CASS; Epi Cell. Deep Dive-implication des tradipraticiens, 2019.

50 CASS; Epi Cell. Deep Dive-Alertes, 2019. 